\title{
GRANITO PERUS (ESTADO DE SÃO PAULO, SE BRASIL): UM CASO DE DIFERENCIAÇÃO EXTREMA DE MAGMA CÁLCIO-ALCALINO ALUMINOSO CRUSTAL
}

\author{
E.Wernick ${ }^{1}$ J.P.Teuppenhayn ${ }^{2}$
}

O magma "Pirituba" representa um magma cálcio-alcalino aluminoso crustal que se manifesta no Estado de São Paulo através do maciço Mairiporã $\left(\sim 40 \mathrm{~km}^{2}\right)$ e do batólito Cantareira $\left(\sim 390 \mathrm{~km}^{2}\right)$ além dos pequenos corpos Taipas, Morro do Perus e do turmalina granito pegmatítico Perus, satélites marginais ocidentais do batólito Cantareira.

Com exceção do corpo Perus, os demais são intrusões múltiplas constituídas dominantemente por biotita granodioritos/monzogranitos megaporfiríticos desprovidos de hornblenda aos quais se associam microgranitos, aplitos e pegmatitos. Já o granito Perus compreende três fácies magmáticas: granito bandado, pegmatitos simples e pegmatitos complexos, todos portadores de quantidades variáveis de turmalina. 0 magma "Pirituba" resulta da interação de fundidos da crosta inferior com metassedimentos/fluídos ricos em boro da crosta superior representada pelo Grupo São Roque.

Dados petrográficos, mineralógicos, químicos e isotópicos mostram que a evolução do magma "Pirituba" se faz segundo a seguinte sequêencia: Granito Porfiróide Mairiporã $\rightarrow$ Cantareira+Taipas $\rightarrow$ Morro do Perus $\rightarrow$ Microgranitos+Aplitos dos granitos porfiróides $\rightarrow$ Perus, Granito Bandado $\rightarrow$ Perus, Pegmatitos Simples $\rightarrow$ Perus, Pegmatitos Complexos e o processo termina com fenômenos hidrotermais/pneumatolíticos simultâneos e posteriores à fase magmática residual. A diferenciação extrema do magma "Pirituba" resulta da retomada do processo inicial de fracionamento (Estágio Mairiporã-Morro do Perus) pela extração de parte do magma residual aplítico que constitui o magma "Perus" que sofre posterior evolução independente enquanto o magma residual não extraído evolui paralelamente para a formação de pegmatitos (Fig. 1). A evolução do magma "Perus" é claramente retratada pela composição das turmalinas magmáticas enquanto a das originadas por processos pneumatolíticos varia com a natureza das rochas (filitos, granitos) metassomatizadas (Fig. 2).

\footnotetext{
${ }^{1}$ DPM, Instituto de Geociências e Ciências Exatas, Universidade Estadual Paulista.

${ }^{2}$ Unweltzentrum Westfalen, Bergkamen, Alemanha.
} 


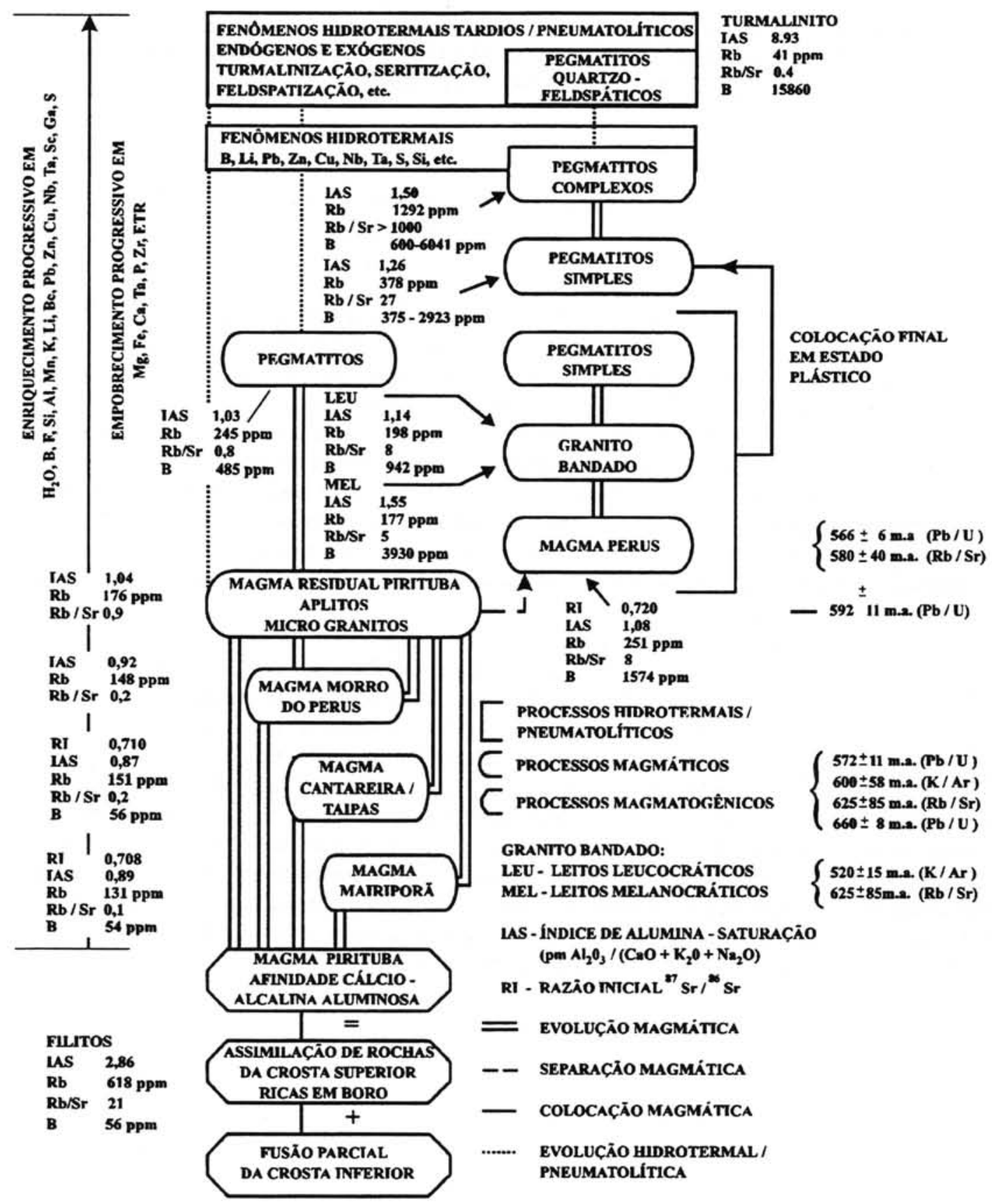

Figura 1 - Gênese e evolução do "Magma Pirituba" nos arredores de São Paulo. 


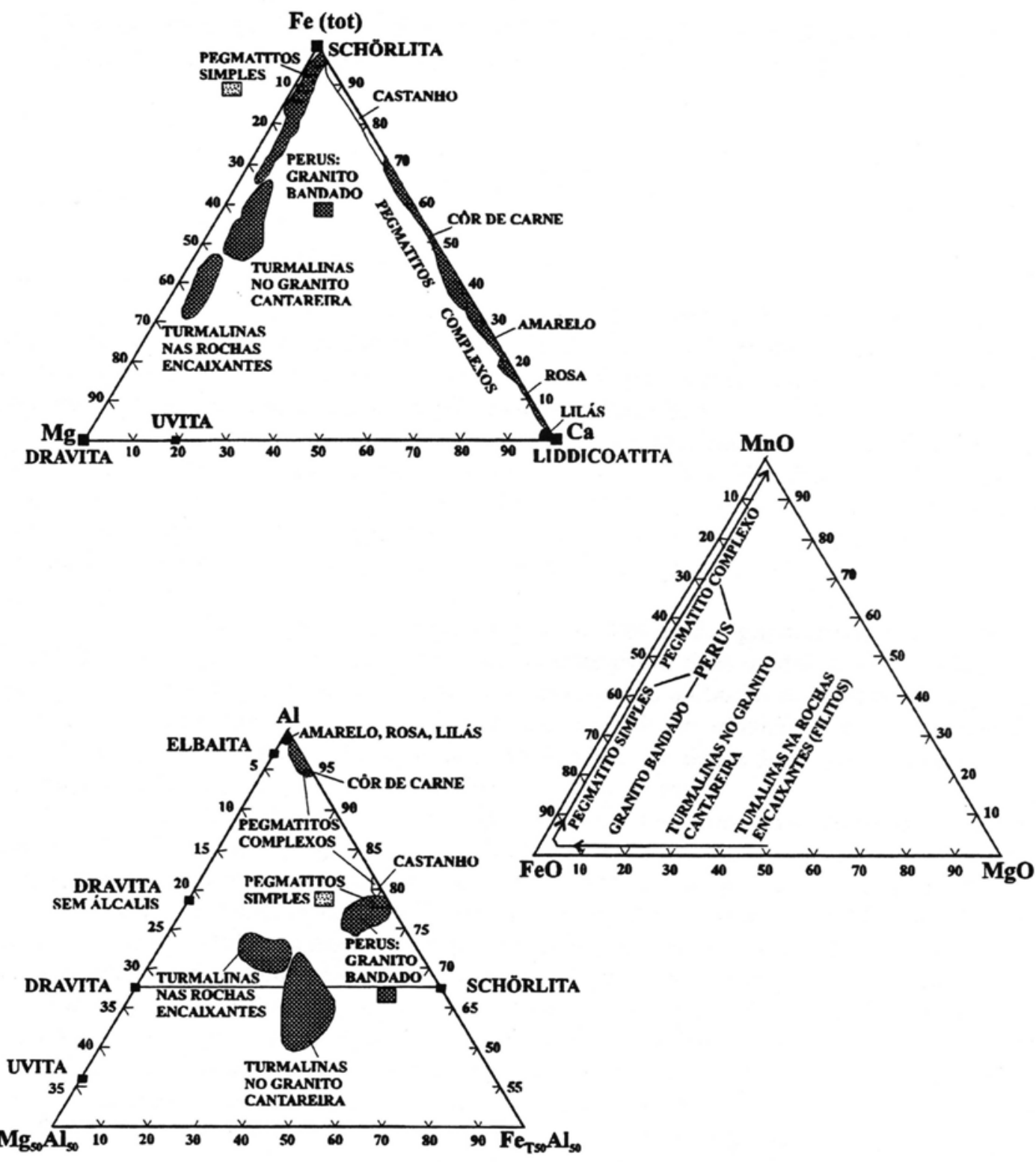

Figura 2 - Composição (e cores) de turmalinas primárias no Granito Perus (fácies granito bandado, pegmatitos simples e pegmatitos complexos) e metassomáticas no Granito Cantareira e nas rochas encaixantes (turmalinitos). Dados segundo Teuppenhayn (1994). 